Journal of

Technology

Management and

Business

\title{
Causes of Accidents Involving Scaffolding at Construction Sites
}

\author{
Nor Haslinda Abas ${ }^{1 *}$, Muhammad Ridhwan Noridan ${ }^{1}$, Muhamad Hanafi \\ Rahmat $^{1}$, Nor Ain Abas ${ }^{2}$, Nur Qamarina Ibrahim ${ }^{3}$ \\ ${ }^{1}$ Jamilus Research Centre, Faculty of Civil Engineering and Built Environment, \\ Universiti Tun Hussein Onn Malaysia, Batu Pahat, 86400 Johor, MALAYSIA \\ ${ }^{2}$ Kolej Kemahiran Tinggi Mara Sri Gading, \\ Jalan klaung-Batu Pahat, Batu Pahat, 86400 Johor, MALAYSIA
}

${ }^{3}$ RAF Consult, Jalan Pulai Perdana 11/1, Taman Sri Pulai Perdana, 81110 Johor Bahru, Johor, MALAYSIA

*Corresponding Author

DOI: https://doi.org/10.30880/jtmb. 2020.07.08.007

Received 15 April 2020; Accepted 20 May 2020; Available online 16 June 2020

\begin{abstract}
Fatal accidents related to the use of scaffolds are one of the most common types of fatal accidents at construction sites in Malaysia, as reported by the Department of Occupational Safety and Health (DOSH). Therefore, the purpose of this study is to investigate the main causes of accidents involving scaffolding at construction sites, based on the perceptions of safety personnel. This study involved collecting data by distributing questionnaires to safety personnel working at construction sites in Johor. Data were analyzed using the Average Min Index and Relative Importance Index (RII). From these studies, the main causes of scaffolding accidents are ignoring safety rules, improper inspections, and improper foundation/stability. The findings of this study provide knowledge and awareness of the causes or factors of scaffolding accidents at construction sites and serve as a reference to construction employers in understanding the factors contributing to scaffolding accidents.
\end{abstract}

Keywords: Construction safety, scaffolding accident, causes of construction accidents, occupational safety and health

\section{Introduction}

The construction industry is perceived as one of the most hazardous industries in many parts of the world (Chia et al., 2014; Feng et al., 2015; Ahmed, 2019). Frequent accidents at construction sites often include scaffold, ladder and electrical, and power tools (Blazik-Borowa, 2014; Chong \& Low, 2014; Benny and Jaishree, 2017; Sanni-Anibire et al., 2020). Safety and health issues in the construction industry need to be considered mainly due to the high growth of highrise buildings in the country. According to the statistics of the accident by sector from 2013 until 2017, the construction sector occupies the highest number of deaths recorded as compared to other industries (DOSH, 2017). The total number of occupational fatal injuries for construction was increased from 36.13\% (out of 10 total industry) in 2013 to $41.47 \%$ in

*Corresponding author: nhaslin@uthm.edu.my

2019 UTHM Publisher. All rights reserved.

penerbit.uthm.edu.my/ojs/index.php/jtmb 
2017. In 2019 (until October), the number of fatalities recorded in the construction industry was 72 out of 214 number of fatalities recorded in all industries, with the percentage of $33.6 \%$ (DOSH, 2019) regardless of the smaller number of accidents happened in the construction industry if compared to other industries. This clearly shows that the construction sector was among the main contributor to the increase in the number of fatalities for occupational fatal accident statistics in Malaysia.

There are many types of accidents in the construction site that cause fatality. One of the main contributors to the accident at the construction site is due to working at height, such as scaffolding works. The main function of scaffolding is to support building works at heights as well as at places with poor access. Other than that, scaffolding also being used in other fields such as for renovation work, supporting the construction of billboards, and temporary hall construction. Due to the various function of scaffolding, there are possibilities of hazardous occurrences related to the unforeseeable activity that endangers the worker in the area of scaffolding such as injuries or falling down of scaffolds outside the building sites (Ayob et al., 2018; Liy et al., 2016; Salim et al., 2017; Blazik-Borowa, 2014).

Scaffolding accidents could happen in two ways, either due to fall from the scaffold or the collapse of the scaffold (Hamdan \& Awang, 2015). Analysis of the fatal accidents involving scaffolding in Malaysia revealed that there were about 20 fatal accidents reported to the Department of Occupational Safety and Health (DOSH) from 2010 until March 2020 (DOSH, 2020). Out of the total 20 number of fatal accident cases reported, 19 cases (95\%) were accounted for fall from a height, whereas 1 case (5\%) was due to collapse of scaffold. Most of the accidents were reported in Johor (6 nos.), followed by Kuala Lumpur (4 nos.), and Pulau Pinang, Melaka, Kedah, and Selangor (2 nos each) (DOSH, 2020). Among the factors identified as the causes to the accidents were due to inexistence or inadequate barrier, unsafe act by workers such as not wearing proper PPE (safety harness), fail to perform risk analysis on the scaffold dismantling procedure, defect scaffold components, incompetent erector, inadequate maintenance, no/inadequate supervision, inadequate training, and unsafe workplace condition. Most of the mentioned cause was 'no safe working procedure', in which 5 cases were reported.

This study suggests that, in order to constrain the rate of accidents involving scaffold from getting serious, it is important to identify the causes of accidents involving scaffold at the construction site so that the precaution measurements can be taken. Therefore, the purpose of this study is to study the main causes of accidents involving scaffold at the construction sites, and further control measures to present scaffolding-related accidents.

\section{Causes of Accident involving Scaffold at Construction Site}

Causes of accidents involving scaffolding can be categorized into several factors such as technical factors, environmental factors, human factors and organizational factors. All of the factors are explained in the following sections.

\subsection{Technical Factors}

Technical factors are usually related to the deficiencies in the plant, equipment, tools, materials handling system, general work environment, etc. Examples of the technical factors for scaffold accidents are the improper foundation, failure at attachment points, inadequate fall protection, unsafe structure design, overloaded scaffolding platforms, incompetent erector, insecure or non-existing bracing and material handling.

\subsubsection{Improper Foundation/Stability}

In most cases, scaffold collapse is due to an inadequate foundation. Hola et al. (2017) in his study revealed that insufficient stability of scaffolding was the main cause of the fatal accident at the construction site. A scaffold can be collapsed due to several reasons such as when the foundation capacity unable to withstand the loads from scaffold structure and scaffold is placed on an uneven surface. For heavier scaffolds, a substantial sole plate needed to be placed under the base plates by following the standards (Blazik-Borowa, 2014).

\subsubsection{Failures at Attachment Points and Parts}

Insufficient components of scaffold support and guardrails could be the cause of scaffold failure. These two factors have a direct impact on the load-bearing capacity of the scaffolding and the possibility of failure (Enshassi \& Shakalaih, 2015). For supports, the strength of scaffolding support depends on the condition of the soil substrate. Usually, the scaffold was placed on pavement or concrete. If the scaffold was planned to be mounted directly onto the ground, it should be leveled and compacted earlier. The ground substrate due to poor compaction. For guardrails, it was bent both in the plane and out of the scaffolding plane. The permanent dismantling of guardrails in the area of transport was common. When the guardrails had not been assembled correctly and following the proper procedure, it could cause a dangerous situation and create a false sense of safety (Enshassi \& Shakalaih, 2015). 


\subsubsection{Inadequate Fall Protection}

According to Shepherd (2000), unguarded scaffold such as missing guardrail and inadequate cross bracing is one of the most common causes of falls associated with the use of supported scaffolds. In Malaysia, the requirement of guardrail for the scaffold is highlighted in Regulation 88, Building Operations and Works of Engineering Construction (Safety) (BOWEC) Regulation 1986, as follows:

'(1) .... every side of a working platform or working place, being a side thereof from which a person is liable to fall a distance of more than 3 meters, shall be provided with a suitable guard-rail or guard-rails of adequate strength to a height of at least one meter above the platform or place and above any raised standing place on the platform, and with toe-boards up to a sufficient height being in no case less than 200 millimeters and so placed as to prevent so far as possible the fall of persons, materials and tools from such platform or place.

(2) The guard -rails and toe-boards used on a working platform or working place shall be placed on the inside of the uprights, and the space between any toe-board and the lowest guard-rail above it shall not exceed 690 millimeters.'

An example of a fatal case due to inadequate fall protection reported by DOSH was when a construction worker died as a result of falling from a height of 7.2 meters. He was working on scaffolds at the time of the incident. The accident investigation revealed that the cause of the accident was due to the no railing on the scaffold (DOSH, 2020). Therefore, providing safety precautions in both fall protection and guardrails can help workers to make sure they are following all the proper procedures to avoid any potential accidents (Hamdan \& Awang, 2015).

\subsubsection{Unsafe Structure Design}

In Malaysia, Regulation 75 of BOWEC 1986 sets the requirements for metal tube scaffolds exceeding 40m and other types of scaffolds exceeding $15 \mathrm{~m}$ to be built in accordance with the design and drawings of Professional Engineers (PE). Inaccurate design or scaffolding without PE design can result in design failure and causing the scaffold to collapse. One case related to this factor has occurred in the UK where scaffolds did not fit with the design. The results show that the structure was not designed to be covered with sheeting and withstand the wind loads which cause the collapse (The Construction Index, 2011). Enhassi \& Shakalaih (2015) found that factors related to unsafe scaffold design such as neglecting the impact of wind loads on scaffolding are major contributing factors to scaffolding in the Gaza Strip. They also mentioned that there was no design for scaffolding in any building on the Gaza Strip due to the non-existence of regulation.

\subsubsection{Overloaded Scaffolding Platforms}

Excessive loading on scaffolding is a common cause of scaffold failure (Cochran, Kroll, \& Associates, n.d.). The scaffolding accident in Australia in 2009 was due to an overloaded brick-filled platform and the design was modified without reference to qualified designers or engineers (Worksafe Victoria, 2012). The accident resulted in injuries to the workers involved. In addition, Williams et al. (2018) found that excessive loading on scaffolding was among the 10 major causes of accidents related to the collapse of the construction industry that respondents felt in Nigeria.

\subsubsection{Incompetent Erector}

Improper installation of the scaffolding by the incompetent scaffolding installers may result in the installation that does not meet the standards which can result in the turnover and displacement of frames on their connections. It has been proven that imperfect scaffolding can lead to decreased load capacity due to the bending of scaffold components, thus affecting scaffold stability (Hamdan \& Awang, 2015). Hola et al. (2018) identify that improper scaffolding structure is one of the leading causes of scaffolding accidents in Poland. According to Hola et al. (2018),

'An inadequate spatial structure of a material agent results from the incorrect assembly of scaffolding. The main irregularities include a lack of vertical communication divisions that allow safe movement of workers between the levels of working platforms, a lack of full working platforms and also necessary structural elements such as anchors, struts, handrails, platforms and earthing.'

Benny and Jaishree (2017) and Enhassi \& Shakalaih (2015) also agreed that improper erections were the major reason for scaffolding hazards. This result reflects the importance of the presence of competent engineers on the site to reduce fall accidents (Enhassi \& Shakalaih, 2015). Benny and Jashree (2017) suggested that erection, movement and dismantling scaffolding should be done under the supervision of qualified persons. 


\subsubsection{Insecure or Non-Existent Bracing}

The use of bracing on scaffolding is crucial to ensure adequate scaffold support and stability. According to Regulation 77, BOWEC 1986, every scaffold shall be securely supported or suspended and where necessary sufficiently and properly strutted or braced to ensure stability. All structures and appliances used as supports for scaffolds, working platforms, gangways, or runs shall be of sound construction, have a firm footing or be firmly supported, and shall, where necessary, be sufficiently and properly strutted or braced to ensure stability. Meanwhile, Regulation 97 of BOWEC emphasizes that posts shall be kept plumb during erection and the scaffold shall be subsequently kept plumb and rigid through adequate bracing.

According to Bakar et al. (2008), scaffolds can be affected if the ties are loose, lost, or inadequate. When this happens, the scaffold can collapse and cause injury to workers or anyone around the area. Therefore, with full attention and focus on the buffer for the support and stability of the scaffold, the incident is inevitable.

\subsubsection{Material Handling}

Material handling refers to the delivery, movement, storage and control of materials and other products. Material handling is a requirement in construction site and improper operation would result in operator and casualties' injuries. Efficient handling and storing of material are vital at the construction site (Tabassi, 2016). Poor handling and storage of materials often results in high injuries and resulting in an additional cost for the recovery (Enshassi \& Shakalaih, 2015).

\subsection{Environmental Factors}

A safe, clean and orderly construction site environment is critical to ensuring employee safety. Environmental factors refer to conditions at the construction site that need to be handled carefully and properly. Without proper management, it can cause unsafe hazards and potentially endanger all workers on site. For environmental factors, this involves weak / defective planking and changes in environmental factors.

\subsubsection{Weak/Defective Planking}

Plank setup is one of the important parts for scaffolding as it holds the temporary load. Many accidents reported on the scaffolding were due to the faults while assembling the plank (Enshassi \& Shakalaih, 2015). If the plank of the scaffold is unstable, insecure, poor condition, and overloaded, it could be easily slid off and break (IHSA.ca., n.d.). Thus, it is very important to use proper material and inspect the plank carefully to avoid any accident.

\subsubsection{Changing Environmental Conditions}

The different working environments and a variety of natural phenomena such as rain and wind can cause unpredictable fatalities on site. Working under direct sunlight for a long period may cause heat rashes, heat exhaustion, and heatstroke. This could lead to more serious health-related issues, and accidents especially to those who are working at a high place (Promsorn et al., 2015). It is the job of supervisors at a construction site to keep track of weather conditions such as high winds, which may cause scaffolds to collapse and lead to serious injuries and fatalities (Enshassi \& Shakalaih, 2015). Work should be suspended or stopped when dangerous conditions pose such hazards to workers on scaffolds. Work should be resumed only when conditions improve.

\subsection{Human Factors}

Human factors are referred to as the ability to work with and through other people who are very important in the construction business because of the involvement of various stakeholders and their labor-intensive nature. Erecting the scaffolding without the presence of competent engineers to monitor work progress can result in unsafe scaffold installation. Accidents caused by human factors contribute to increased accidents at construction sites. The following are human factors that result in scaffolding accidents; insufficient or inadequate training at work, improper use of protective equipment, and violation of safety regulations.

\subsubsection{Insufficient or Lack of On-the-Job Training}

An unskilled worker means that the job is done by someone who has no specialized skills and almost no formal education. Proper training for employees is the key to ensuring safety in the construction site. Many project managers assume that all workers are aware of construction site safety procedures at work. Unfortunately, most of them are unskilled and new employees. Without the training provided to them, it would be impossible for workers to complete their tasks well, contributing to an increase in cases of injuries and fatalities at construction sites (Hamdan \& Awang, 2015; Nowobilski \& Hola, 2019). 


\subsubsection{Improper Use of Personal Protection Equipment (PPE)}

Personal protective equipment (PPE) is a tool that protects consumers from health or safety risks (injuries or infections) at work such as safety helmets, gloves, eye protection, high-visibility clothing, safety footwear, and safety harness. It also includes respiratory protective equipment. Ideally, the best approach is to maintain a safe work environment and eliminate potential hazards. The PPE should only be relied upon as the last line of defense in place where it is not practicable to control the hazards at source. The use of personal protective equipment means working in a potentially hazardous work environment and is a key method of injury prevention. Therefore, it is important to ensure that the equipment selected is reliable and effective, used and maintained properly, and that the user has received adequate training. Without putting on the PPE while at the construction site, all workers are at higher risk in exposing themselves to injuries and accidents (Blazik-Borowa, 2014; Hola et al., 2017; Hola et al., 2018; Nowobilski \& Hola, 2019).

\subsubsection{Ignoring Safety Rules}

Special attention should be given to each worker at the construction site. This is because the rate of accidents that occur at the construction site continues to increase and is alarming. By ignoring safety regulations on construction sites, this could result in unwanted incidents as it makes the construction site a high risk area for accidents. Accidents can happen anytime and anywhere. It can cause serious injury and may endanger the life of the employee. By adhering to safety regulations, such accidents can be avoided (Kanchana et al., 2015; Hola et al., 2017; Hola et al., 2018; Whitaker et al., 2003; Nowobilski \& Hola, 2019).

\subsection{Organizational Factors}

A construction project was normally leading by a project manager who would be the person that organize and assign roles to the workers as well as setting the deadlines and targets to achieve for the project. In order to achieve the target, all workers should know their role and need to understand their tasks properly. Without knowledge, it could delay the project and produce work with poor quality. Guidance from the management is crucial to ensure that all employees are kept safe at construction sites. The followings are the organization-related factors for scaffold accidents, which are no safe work procedure, lack of monitoring by the site supervisor, communication problem/break down, and improper inspection.

\subsubsection{No Safe Work Procedure}

Safe work procedures are standard procedures for performing tasks at the workplace. The purpose is to reduce the risk for health and safety at the workplace and the likelihood of an injury by ensuring that all workers practiced safety procedures while carrying out the tasks assigned to them. This standard procedure will be most effective if it is made clear to the workers, the right tools for the job are provided to them and they are supervised by skilled people. A thorough investigation should be conducted if any unwanted incidents or changes happen in the workplace (Enshassi \& Shakalaih, 2015). No safe work procedure was also the common type of accident causes for fatal accidents involving scaffold in the Malaysian construction industry (DOSH, 2020).

\subsubsection{Lack of Monitoring by Site Supervisor}

Supervisors are responsible for daily chores at the workplace. Supervisors should ensure a safe and healthful workplace for employees. Employees must be able to report unsafe or unhealthful workplace conditions or hazards to a supervisor without fear of reprisal. Whether it is a large or small construction site, good supervision always played an important role to prevent any accidents to occur. Good supervisory roles include planning and allocating work, making decisions, monitoring performance and compliance, providing leadership and building teamwork, and ensuring workforce involvement. Heavy supervision involved in the implementation of specialized construction projects and particular health and safety management. Without effective monitoring by the site supervisor, it endangers the health and safety of all the workers at the construction site (Hola et al, 2018; Nowobilski \& Hola, 2019; Hamdan \& Awang, 2015).

\subsubsection{Communication Problem/Break Down}

Communication is an important part of the construction industry. Common problems in construction are often referred to as communication problems. The efficiency and effectiveness of the construction process strongly depend on the quality of communication. Failure to communicate can ultimately lead to a serious accident, project rework, and employee problems at the construction site. Unsuccessful, and inadequate and inefficient processes in the communication of project information that should be avoided in the construction industry. It could be either on a large scale or small scale. On a large scale, it forms between construction parties such as consultants, clients, and contractors. While on a small scale, it occurs between the individual in the same firm (Hola et al., 2017; Hamdan \& Awang, 2015). 


\subsubsection{Improper Inspections}

The company or employer should appoint a skilled and qualified person in handling the scaffolding. Careful attention is required to inspect the scaffolding. Their responsibilities are to inspect and maintain the scaffolding so that it is safe to use while performing height -level work. On top of that, the hand-over and post-over process and after repair or modification work also demanded a full checkup by the skilled person to do the inspection (Safework Australia, 2014; Enshassi \& Shakalaih, 2015).

\section{Methodology}

This study adopted the questionnaire survey method to attain respondents' insights on the significant factors that cause accidents involving scaffolding at construction sites. The questionnaire consisted of 2 parts: Part 1 dealt with attaining respondent's demographic profile, and Part 2 consisted of questions related to factors that cause accidents involving scaffold at construction sites. For Part 2, the respondents were required to choose the degree of significance of each factor based on the 5-point Likert Scale, ranging from 1 (strongly insignificant) to 5 (strongly significant).

\subsection{Data collection procedure}

A pilot study was conducted before distributing the actual questionnaire, which involved several panels of experts, to ensure the validity and reliability of the survey instrument. The questionnaire survey instrument was revised based on comments from experts before being distributed to the respondent for the actual data collection process.

The validated questionnaire was distributed to 150 safety personnel who were involved in construction projects in Johor through the online platform such as email and WhatsApp; and also through self-administered. The respondents had included Safety and Health Officers (SHO), Safety Promoters, Site Safety Supervisors (SSS), and Safety Managers. Since the population of the respondents for this study was unknown, the minimum sample size was determined by using the following formula (Krejcie \& Morgan, 1970):

$$
\text { Sample Size, } \mathrm{SS}=Z^{2} \times P \times(1-P) / C^{2}
$$

Where $\mathrm{Z}$ is $\mathrm{Z}$ value (for $95 \%$ confidence level = 1.96), $\mathrm{P}$ is percentage picking a choice (in decimal) and 0.5 used for sample size needed, and $\mathrm{C}$ is Margin of error ( $9 \%$ ). From the calculation, the minimum number of respondents required to represent the population of the study is 119 respondents. This study achieved 119 returned questionnaires, which achieved the minimum sample size requirement. Some of the respondents of the survey were closed contacts with the researchers, thus high completion rate was achived. The questionnares were also distributed by respondents to their colleagues, which increased the number of returned questionnaire.

\subsection{Measures for Data Analysis}

All of the data obtained from the questionnaire was analyzed to find the significant factors that caused accidents involving scaffolding. There were two tests involved in analyzing the data, which were the Average Mean Index Method and Relative Importance Index (RII). The value of Cronbach's Alpha was 0.963, which meant that the internal consistency of the questionnaire data was excellent (Gliem \& Gliem, 2003).

\subsubsection{Average Mean Index}

In order to identify the significant factors that cause accidents involving scaffolding at the construction site, respondents' answers in Part 2 of the questionnaire were analyzed using the Average Mean Index formula as below:

$$
\text { Average Mean Index }=\frac{\sum\left(\mathrm{a}_{i} \mathrm{n}_{i}\right)}{\sum \mathrm{n}_{\mathrm{i}}}
$$

Where:

$\mathrm{a}_{\mathrm{i}}=$ The number to each factor by the respondents

$\mathrm{x}_{\mathrm{i}}=$ The total of frequency by the respondents

$i=$ Total targeted number of respondents

The value of the Average Mean Index was then categorized based on the Level of Factor as in Table 1.

Table 1 - Mean Index for Level of Factor (Adopted from Majid et al., 1998)

\begin{tabular}{cc}
\hline Mean Index & Level of Factor \\
\hline $\mathbf{1 . 0 0} \leq$ Total Index $<\mathbf{1 . 5 0}$ & Very Insignificant
\end{tabular}




\begin{tabular}{|c|c|}
\hline $1.50 \leq$ Total Index $<2.50$ & Insignificant \\
\hline $2.50 \leq$ Total Index $<3.50$ & Moderate \\
\hline $3.50 \leq$ Total Index $<4.50$ & Significant \\
\hline $4.50 \leq$ Total Index $<5.00$ & Very Significan \\
\hline
\end{tabular}

\subsubsection{Relative Importance Index (RII)}

Relative Importance Index analysis was selected in this study to rank the characteristic based on their relative importance Gunduz, 2013). After the determination of the Relative Importance Index (RII), the ranking based on the value of RII was done accordingly from the most value to the least. The formula was used to calculate the Relative Importance Index (RII) was Relative Importance Index, $\mathrm{RII}=\Sigma W /(A \times N)$, where $\mathrm{W}$ was the weight given to each factor by the respondent that was ranging from $1-5, \mathrm{n}$ is Rate from 1-5, A was the highest weight, and $\mathrm{N}$ was the total number of respondents.

\section{Analysis and Discussion}

Based on the analysis of 119 returned and completed questionnaires, the average index analysis and RII were performed.

\subsection{Background of Respondents}

Fig. 1 shows the background of respondents. The majority of respondents of this study worked as Site Safety Supervisor (SSS), possessed a Diploma, and had between 2 to 5 years of working experience. It is noted that the majority of the respondents $(71.8 \%)$ had less than 5 years of working experience. One may question the level of experience and knowledge of the respondents that would affect the credibility of the research findings. However, the reliability of the study was ensured through the Cronbach's Alpha result that proved the reliability of the internal consistency of the test. Moreover, the respondents were solely responsible for occupational safety and health (OSH) matters. Even though they had less experience, their knowledge of the subject matter might be high since they were continuously dealing with OSH, especially on accident prevention.

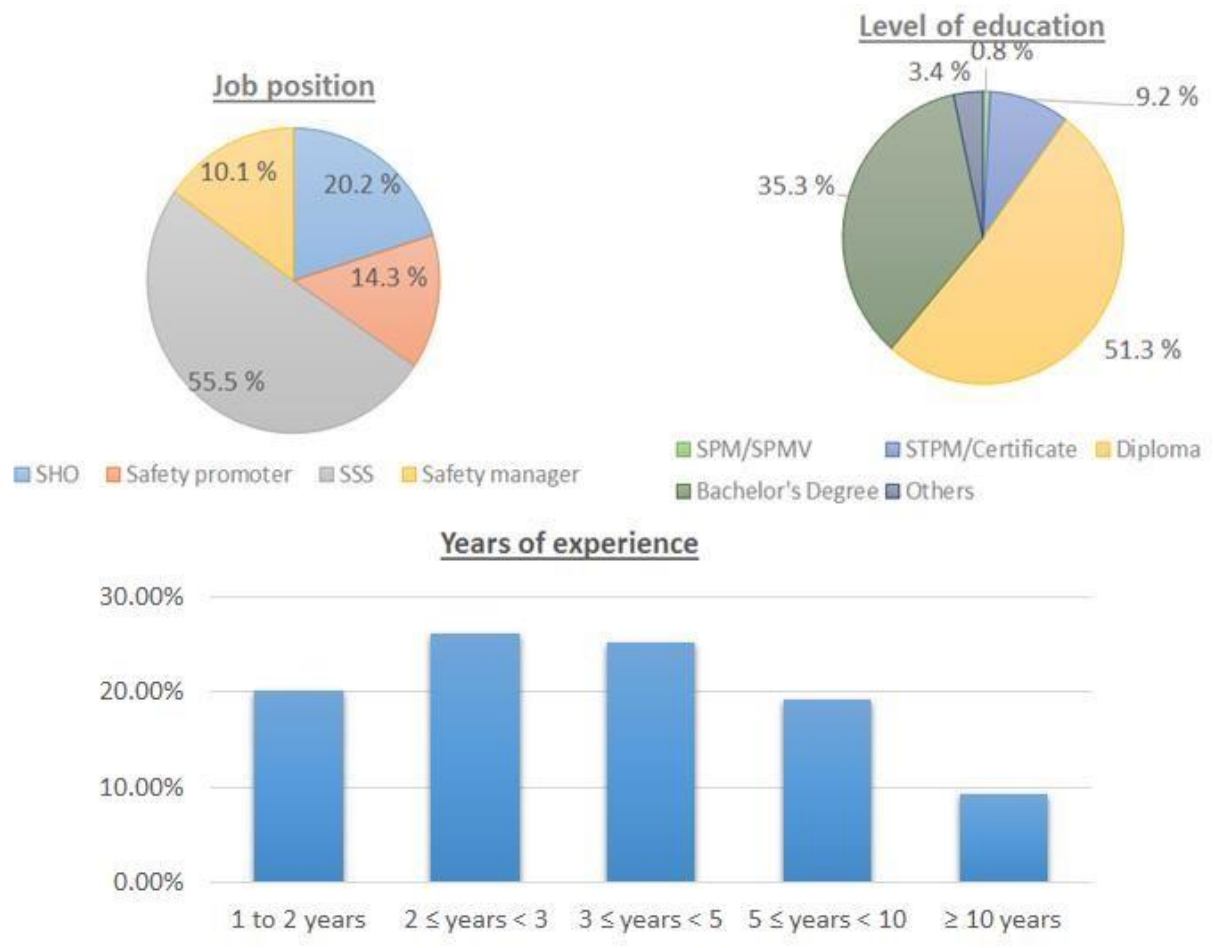

Fig. 1 - Background of respondents 


\subsection{Significant Causes of Scaffolding-Related Accident at Construction Site}

Table 2 summarizes the analysis of the Average Mean Index and RII in determining the significant factors that cause accidents involving scaffolding at construction sites. As can be seen in the table, all the factors listed in the questionnaires were considered significant in causing scaffolding-related accidents.

Table 2 - Summary of respondent's answer and mean index for significant causes of scaffolding-related accident at construction site

\begin{tabular}{|c|c|c|c|c|c|}
\hline No. & Significant Causes of Scaffolding-Related Accident & $\begin{array}{l}\text { Mean } \\
\text { Index }\end{array}$ & $\begin{array}{l}\text { Level of } \\
\text { Factor }\end{array}$ & RII & $\begin{array}{c}\text { Ranking } \\
\text { Based on } \\
\text { RII }\end{array}$ \\
\hline 1 & Ignoring safety rules (Human factor) & 4.36 & Significant & 0.872 & 1 \\
\hline 2 & Improper inspections (Organizational factor) & 4.29 & Significant & 0.859 & 2 \\
\hline 3 & Inadequate foundation/stability (Technical factor) & 4.29 & Significant & 0.857 & 3 \\
\hline 4 & Failures at attachment points and parts (Technical factor) & 4.24 & Significant & 0.849 & 4 \\
\hline 5 & Overloaded scaffolding platforms (Technical factor) & 4.17 & Significant & 0.834 & 5 \\
\hline 6 & Inadequate fall protection (Technical factor) & 4.16 & Significant & 0.832 & 6 \\
\hline 7 & Unsafe structure design (Technical factor) & 4.16 & Significant & 0.832 & 6 \\
\hline 8 & $\begin{array}{l}\text { Insufficient or Lack of on-the-job training (Human } \\
\text { factor) }\end{array}$ & 4.16 & Significant & 0.832 & 6 \\
\hline 9 & Incompetent erector (Technical factor) & 4.15 & Significant & 0.830 & 9 \\
\hline 10 & No safe work procedure (Organizational factor) & 4.13 & Significant & 0.827 & 10 \\
\hline 11 & $\begin{array}{l}\text { Lack of Monitoring by Site Supervisor (Organizational } \\
\text { factor) }\end{array}$ & 4.13 & Significant & 0.825 & 11 \\
\hline 12 & Material Handling (Technical factor) & 4.11 & Significant & 0.822 & 12 \\
\hline 13 & Weak/Defective planking (Environmental factor) & 4.07 & Significant & 0.813 & 13 \\
\hline 14 & Insecure or non-existent bracing (Technical factor) & 4.03 & Significant & 0.807 & 14 \\
\hline 15 & $\begin{array}{l}\text { Improper Use of Personal Protective Equipment (PPE) } \\
\text { (Human factor) }\end{array}$ & 4.03 & Significant & 0.805 & 15 \\
\hline 16 & $\begin{array}{l}\text { Communication Problem/Break down (Organizational } \\
\text { factor) }\end{array}$ & 3.97 & Significant & 0.795 & 16 \\
\hline 17 & $\begin{array}{l}\text { Changing environmental conditions (Environmental } \\
\text { factor) }\end{array}$ & 3.95 & Significant & 0.790 & 17 \\
\hline
\end{tabular}

The highest score for average mean index analysis was 'ignoring safety rules' with the value 4.36, followed by 'improper inspection' (4.29) and 'improper foundation/stability’ (4.29). The least perceived significant factors were 'changing environmental conditions' (3.95), 'communication problem/breakdown' (3.97), and 'improper use of Personal Protective Equipment (PPE)’ (4.03). Results from RII had also shown similar patterns in terms of ranking from high to low.

Ignoring safety rules scored the highest among others, agreeing with the previous study by Kanchana et al. (2015) and Enshassi et al. (2015). According to Mustapha et al (2015), the majority of accidents occurred when employees ignored safety rules and management ignored the presence of unsafe conditions. This has made accident prevention a challenging effort as risk is beyond human intervention. Hole et al. (2018) in their study highlighted several employee's unsafe acts related to ignoring safety rules that cause scaffold accident such as dismissing hazards that arise from the use of scaffolding that was not completely assembled or the movement of an employee on the outer edge of scaffolding; employees not using personal protective equipment; employee not using a security line that protects against falling or unauthorized unfastening from fixed elements. Ignoring safety rules is considered as unsafe acts that pose a serious threat to safety management (Emuze, 2017). Therefore, all concerned parties should be committed to obeying safety rules so that accidents caused by unsafe acts could be prevented in the construction industry (Emuze, 2017).

Meanwhile, improper inspections of the scaffold and its working area are the second-highest factor of scaffold accidents. This is in line with the previous study by Hola et al. (2017) and Nobowilski \& Hola (2019). Inspection of the scaffold should be carried out according to Regulation 74 of BOWEC 1986, during erection, alteration, and dismantling of the scaffold. The inspector should also inspect the material to be used on the scaffold. In spite of that, it is important to carry out the inspection on scaffolding works regularly (for example once in 7 days), so that any weaknesses or problems occurred at sites can be solved on time and early action can be taken to prevent accidents. Halperin \& McCann 
(2004) suggested that a triage method for scaffold inspections should be developed, in which every scaffold is inspected using the rapid four-factor method (a) planking, (b) railings, (c) access, and (d) tying off to buildings.

The next top 5 factors causing scaffold accidents are related to technical factors which are inadequate foundation/stability, failures of attachment points and parts, overloaded scaffolding platform, inadequate fall protection, and unsafe structure design. These factors were also highlighted as the main causes of scaffold accidents in Hola et al. (2017), Blazik-Borowa (2014), Enshassi \& Shakalaih (2015) and Hamdan \& Awang (2015), Cochran, Kroll and

Associates (n.d.) and Williams et al. (2018). Therefore, ensuring all the technical aspects above are in good condition and also ensuring compliance to the load limit of the working platform, scaffold structural design, and adequate fall protection is important in order to prevent scaffold collapse. Other related main factors for scaffold accidents are material handling, weak/defective planking, and insecure or non-existent bracing.

All the factors above can be attributed to the next important factor that causes scaffold accidents which is insufficient or lack of on-the-job training and incompetent erector. It is important for all parties involved in scaffolding work such as an inspector, erector, safety personnel, supervisor, and workers to possess good technical skills, training, and experience related to the scaffold (Enshassi, 2003) to ensure the successfulness of the technical measures taken and complied with. This is in line with Halperin \& McCann (2004) who found that there was a highly statistically significant correlation of the scaffold safety training of the competent person present on the site; the person who erected the scaffold; and (d) the number of workers present on the site, to a high overall scaffold safety rating.

Next scaffold accident factors are related to the organizational factor which is no safe work procedure and lack of monitoring by the site supervisor, followed by improper use of PPE, communication problem, and changes in environmental condition. The management of the workplace plays an important role to ensure a safe workplace by providing proper arrangements related to safe working procedure preparation and implementation. It is important for each worker to be equipped with proper and adequate PPE and has been thoroughly trained in safe work practices when working on scaffolding. With regards to supervision, this study agreed with Low et al. (2018) in that safety supervision and inspection should be referred to frequency, broadness, and depth of safety supervisions and inspections on site.

This is in line with Fung et al.'s (2005) study that there is a highly negative no correlation between safety supervision and risk-taking behavior among construction workers in Hong Kong. Low et al. (2018) suggested that the management should be aware of the problems related to safety supervision and inspection, such as employing additional human resources to ensure adequate safety supervision and inspection for construction workers, thereby reducing their risktaking propensity. In addition, the management should also ensure effective communication with regards to scaffold such as hazard communication through briefing, training, and instructions. Finally, the least perceived factor of scaffold accident is related to an environmental condition such as rain, high wind, and the presence of toxic gases. Lipscomb et al (2003) suggested that it is not possible to change the weather, therefore the workers' behaviors need modifications based on the weather and dangerous conditions. Supervisors and safety personnel such as safety and health officer at the workplace should play a role in assisting the management to prevent the scaffold accident by regularly remind the workers on the actions they should take if dangerous events happen, and should always monitoring the scaffolding works at the site.

The researchers suggest that, in order to mitigate the number of accidents involving scaffolding, preventive measures should be taken seriously. This study suggests preventing accidents should be traced back to the causes of accidents. Some suggestions for accidents involving scaffolding preventive measures include provide proper and adequate training to employees, ensure proper guardrail or barrier is installed, ensure the stability of scaffold foundation, implement safe working procedure, material handling management, good communication practice, the use of safety net or peripheral netting and suitable PPE (safety harness). Training is deemed as an inexpensive yet essential measure to mitigate accidents and should be given to all workers as they are exposed to different kinds of hazards at the construction site (Benny \& Jaishree, 2017). This is also supported by the other author such as Selvam \& Priyadarshini (n.d.) and Brace et al. (2010).

\section{Conclusion}

One of the accident types at the construction site is due to scaffold accidents. There are many factors contributed to the accidents involving scaffolding at construction sites. This study presented the causes of scaffold accidents at construction sites, form the perceptions of the safety personnel who are working at construction sites in Johor, Malaysia. There were seventeen (17) causes or factors relevant to scaffold accidents identified from the literature review and were categorized into technical factors, human factors, environmental factors, and organizational factors. Average mean index analysis revealed that all 17 factors were found to be significant in causing scaffold accidents. Meanwhile, the analysis of RII revealed that the top 3 factors of scaffold accidents were ignoring safety rules, improper inspections, and improper foundation/stability. Whilst the least significant causes were found to be changed in environmental conditions, followed by communication problems or breakdown and improper use of personal protective equipment (PPE).

The findings of this study provide knowledge and awareness of the causes or factors of scaffold accidents at construction sites. The study participants were security personnel, so their perception was useful in determining the true cause of the scaffolding accident as they had first-hand experience of safety and health issues at the construction site. Identifying the causes of factors of scaffold accidents is important before suggesting and carrying out preventive 
measures. Based on the findings, the employer (i.e. contractor) can identify the hazard related to the scaffold accident, assess the risk, and implement the recommended control measures.

There are several limitations to be noted in this study, related to the small sample size and limited working experience of respondents. Future study is sought to extend the sample size to other positions such as technical and management staff apart from safety practitioners, such as site engineers, site supervisors, and project managers. Their opinions can also serve as references in helping to make this study successful. Next, the sample size should be selected among those who had more than 5 years of experience to ensure the credibility of research findings. In addition, the distribution of questionnaires should also be involving respondents from other states in Malaysia. This can enhance the generalizability and reliability of the data collected.

\section{Acknowledgement}

The author would like to thank the Ministry of Higher Education, Malaysia for the support and funding given towards completing this research (FRGS Vot 1579). The author would also like to thank the Research Management Centre, Universiti Tun Hussein Onn Malaysia for their assistance in managing the grant.

\section{References}

[1] Ahmed S. (2019). Causes of Accident at Construction Sites in Bangladesh. Organization, Technology and Management in Construction, 19(11), 1933-1951

[2] Ayob A., Shaari A. A., Zaki M. F. M., \& Munaaim M. A. C. (2018). Fatal occupational injuries in the Malaysian construction sector-causes and accidental agents. IOP Conference Series: Earth and Environmental Science, 140, 012095

[3] Bakar N. A., Ismail M. R., \& Lin T. G. (2008). Scaffolding Safety Assessment in Construction Sites in Penang, $2^{\text {nd }}$ International Conference on Built Environment in Developing Countries (ICBEDC 2008), Kuala Lumpur, 1311-1328.

[4] Benny B., \& Jaishree D. (2017). Construction Safety Management and Accident Control Measures, International Journal of Civil Engineering and Technology (IJCIET) 8(4), 611-617.

[5] Blazik-Borowa E. (2014). The analysis of the stages of scaffolding "life" with regard to the decrease in the hazard at building works, Archives of Civil and Mechanical Engineering, 15(2), 516-524.

[6] Brace C. L., Gibb A. G., Pendlebury M., \& Bust P. D. (2010) How can we prevent construction accidents? Outcomes from a stakeholder consultation: societal and industry-wide influences, Proceedings of the Institute of Ergonomics and Human Factors Annual Conference, Keele, 107-115.

[7] Chi C. F., Lin S. Z., \& Dewi R. S. (2014). Graphical Fault Tree Analysis for Fatal Falls in the Construction Industry. Accident Analysis and Prevention, 72, 359-369.

[8] Chong H. Y. \& Low T. S. (2014). Accidents in Malaysian Construction Industry: Statistical Data and Court Cases. International Journal of Occupational Safety and Ergonomics, 20(3), 503-513.

[9] Cochran, Kroll \& Associates (n.d.) 9 Common Causes of a Scaffolding Accident at Construction Sites in Michigan Retrieved on December 15, 2019 from https://cochranlaw.com/accidents-injuries-topics/9-commoncauses-scaffoldingaccident-construction-sites-michigan/

[10] DOSH (2017) Occupational Accident Statistic Retrieved on August 30, 2018 from https://www.dosh.gov.my/index.php/statistic-v/occupational-accident-statistics-v/occupational-accident-2017

[11] DOSH (2019). Occupational Accident Statistic 2019 Retrieved on February 28, 2020 from https://www.dosh.gov.my/index.php/statistic-v/occupational-accident-statistics-v/occupational-accident statistic-2019

[12] DOSH (2020) Fatal Accident Case Retrieved on February 28, 2020 from https://www.dosh.gov.my/index.php/fatalaccident-case-1

[13] Emuze F. (2017). The Human Contribution to Unsafe Construction Acts and Conditions in the Central Region of South Africa. Proceeding of the 33rd Annual ARCOM Conference, Cambridge, UK, 330-339.

[14] Enshassi A. (2003). Factors affecting safety on construction projects. International Conference on Construction Project Management Systems: The Challenge of Integration, São Paulo, 1-6.

[15] Enshassi A., \& Shakalaih S. (2015). Construction Workers Fall Accidents from Scaffolding in Gaza Strip The $6^{\text {th }}$ International Conference on Construction Engineering and Project Management (ICCEPM 2015) (Busan) 15.

[16] Feng Y., Zhang S., \& Wu P. (2015). Factors influencing workplace accident costs of building projects. Saf. Sci., 72, 97-104. 
[17] Fung I. W., Tam C., Tung K. C., \& Man A. S. (2005) Safety cultural divergences among management, supervisory and worker groups in Hong Kong construction industry. Int. J. Proj. Manag., 23, 504-512.

[18] Gliem J. A., \& Gliem R. R. (2003). Calculating, Interpreting, and Reporting Cronbach's Alpha Reliability Coefficient for Likert-Type Scales. Midwest Research-to-Practice Conference in Adult, Continuing, and Community Education, Ohio, 82-88.

[19] Gündüz M., Nielsen Y., \& Özdemir M. (2013). Quantification of Delay Factors Using the Relative Importance Index Method for Construction Projects in Turkey. Journal of Manageemnt in Engineering, 29(2), 133-139.

[20] Halperin K. M., \& McCann M. (2004). An evaluation of scaffold safety at construction sites. Journal of Safety Research, 35, $141-150$.

[21] Hamdan N., \& Awang H. (2015). Safety Scaffolding In The Construction. Jurnal Teknologi, 5, 26-31.

[22] Hoła A., Sawicki M., \& Szóstak M. (2018). Methodology of Classifying the Causes of Occupational Accidents Involving Construction Scaffolding Using Pareto-Lorenz Analysis. Applied Sciences, 8(48), 1-11.

[23] Hoła B., Nowobilski T., Rudy J., \& Błazik E. B. (2017). Dangerous events related to the use of scaffolding. Technical Transactions 7/2017, Civil Engineering, 31-39.
IHSA.ca.
(n.d.). Scaffolds
Retrieved
on February 20,
$20, \quad 2020$

from https://www.ihsa.ca/rtf/health_safety_manual/pdfs/equipment/Scaffolds.pdf

[25] Kanchana, S., Sivaprakash, P., \& Joseph, S. (2015). Studies on Labour Safety in Construction Sites, The Scientific World Journal, 2015, 1-4.

[26] Krejcie, R. V., \& Morgan, D. W. (1970). Determining Sample Size for Research Activities, Educational and Psychological Measurement 38, 607-610.

[27] Lipscomb H. J., Dement J. M., Nolan J., Patterson D., Li L., \& Cameron W. (2003). Falls in Residential Carpentry and Drywall Installation: Findings From Active Injury Surveillance With Union Carpenters. J. Occup. Environ. Med., 45(8), 881-890.

[28] Liy C. H., Ibrahim S. H., Affandi R., Rosli N. A., \& Mohd Nawi M. N. (2016). Causes of Fall Hazards in Construction Site Management. International Review of Management and Marketing, 6(S8), 257-263.

[29] Low B. K. L., Man S. S., \& Chan A. H. S. (2018). The Risk-Taking Propensity of Construction Workers-An Application of Quasi-Expert Interview. Int. J. Environ. Res. Public Health, 15, 1-11.

[30] Majid M. Z. A., \& McCaffer R. (1998). Factors of Non Excusable Delays That Influence Contractor's Performance. Journal of Construction Engineering and Management, Journal of Management in Engineering, 14(3), 42-49.

[31] Mustapha Z., Aigbavboa C. O., \& Thwala W. D. (2015). Application of modified statistical triangle of accident causation in construction health and safety. Proceedings of the 19th International Symposium on Advancement of Construction Management and Real Estate, Berlin Heidelberg, 57 - 66.

[32] Nowobilski T., \& Hola B. (2019). The qualitative and quantitative structure of the causes of occupational accidents on constrcution scaffolding. Archives of Civil Engineering, LXV(2), 121-131.

[33] Olandiran O. J., \& Sotunbo A. S. (2012). Accidents on Building Sites: Rate of Occurrence and Causes, The Professional Builders.

[34] Promsorn P., Soponsakulrat P., Adulyanukosol C., Kaiyarit P., \& Chinda T. (2015). Identifying Root Causes of Construction Accidents: Non - Human Error Factors. International Journal of Computing, Communication \& Instrumentation Engineering, 2(1), 1-5.

[35] Safework Australia (2014). General Guide for Scaffolds and Scaffolding Work Retrived on September 1, 2019 from https://www.safeworkaustralia.gov.au/system/files/documents/1703/scaffolds-scaffolding-work-generalguide.pdf Salim S. M., Romli F. I., Besar J., \& Aminian N. O. (2017). A Study on Potential Physical Hazards at Construction Sites. Journal of Mechanical Engineering, 4 (1), 207-222.

[36] Sanni-Anibirea M. O., Mahmouda A. S., Hassanainb M. A., \& Salami B. A. (2020) A risk assessment approach for enhancing construction safety performance. Safety Science, 121, 15-29.

[37] Selvam, A., \& Priyadarshini, K. (n.d.). Safety Management and Hazards Control Measures in Construction, $97-$ 101.

[38] Shepherd G. (2000). Construction fatalities - the toll of gravitational energy, ISF Symposium (Orlando, Florida).

[39] Tabassi A. A. (2016) Site planning and development. In H. Awang and M. A. O. Mydin (Eds.), Construction methods and technology, Pulau Pinang: Penerbit USM.

[40] Tee K. (2018) One Hurt in Kajang Construction Scaffolding Mishap Retrieved on August 31, 2019 from https://www.malaymail.com/news/malaysia/2018/01/10/one-hurt-in-kajang-construction-scaffoldingmishap/1550055

[41] The Construction Index (2011). Design Failure Caused Scaffold Collapse Retrieved on December 15, 2019 from https://www.theconstructionindex.co.uk/news/view/design-failure-caused-scaffold-collapse 
[42] Whitaker S. M., Graves R. J., James M., \& McCann P. (2003). Safety with access scaffolds: Development of a prototype decision aid based on accident analysis. Journal of Safety Research, 34, $249-261$.

[43] Williams O. S., Adul Hamid R., \& Misnan M. S. (2018) Causes of building construction related accident in the southwestern states of Nigeria. International Journal of Built Environment and Sustainability, 6(1), 14-22.

[44] Worksafe Victoria (2012). Altered Design and Overloading Contributed to Prahran Scaffold Collapse Retrieved on December 15, 2019 from https://www.worksafe.vic.gov.au/news/2012-03/altered-design-andoverloading-contributedprahran-scaffold-collapse 